\title{
Development and Application of Drag Type of Bottom Sealed Packer
}

\author{
Guangfeng Liu, a, Daihong Gu1, 2, b, Chongjun Chai², c, Jinchao Liü, d, Shaojie \\ Pan $^{*, 1}$, Wenju Wang ${ }^{1, e}$ and Yaoxing Bai ${ }^{1, f}$
}

${ }^{1}$ CMOE Key Laboratory of Petroleum Engineering in China University of Petroleum, Beijing, China

${ }^{2}$ Beijing Polydoctor Petroleum Technology Co., Ltd., Beijing, China

"Corresponding author: tiandinaner1990@yeah.net,

a13120197965@163.com, bgudaihong@vip.sina.com, cchj-cm@163.com, dliujinchao.120@163.com, ${ }^{e}$ wangwenju322@126.com, fbaiyaoxing@sina.com

Keywords: packer; rubber sleeve; anchoring; balancing device; sand control device

Abstract. A drag type of continuous layered fracturing bottom sealed packer has been developed to elevate fracturing efficiency. Adopt mechanical lift and lower the string to implement the sealed and unsealed; the sealing structure is simple, rubber sleeve is short and performance of seal is stable; the anchoring is solid, which is suitable for all kinds of grade of steel casing; set the balancing device in the interior of the packer to balance the upper and lower pressure of the glue tube after work is done; sand control device is specially designed on the packer to prevent sand sticking that may occur during operation. The multiple applications on the scene suggest that the performance of drag type of bottom sealed packer is excellent and partly replaces the similar imported products.

\section{Introduction}

In recent years, domestic demand for oil is strong and imbalance between the demand and supply is increasingly prominent, so how develop efficiently the petroleum resources to meet the sustainable development of economic growth in our country has become an important issue. Some research and test applications were carried out in staged fracturing technology of packer on horizontal well after several years of research and application. However, the technology has bigger gap compared with advanced foreign technology, field test applications also appeared a lot of technical problems and related technical research obviously can not meet the rapid development and application of horizontal wells in our country in recent years, so it is necessary to carry out the study to improve the level of continuous layered fracturing technology and greatly improve the economic benefits of development by horizontal wells in low permeability reservoir ${ }^{[1-3]}$.

On the basis of analyzing the advantages and disadvantages of the existing various packer and consulting a large number of technical data in domestic and overseas, develop A drag type of bottom sealed packer suitable for horizontal well's continuous layered fracture through design, test and improvement.

\section{Design Thought}

Packer is mainly composed of sealing parts, support anchor, balancing device and sand control device. Fig. 1 is a structure diagram of packer.

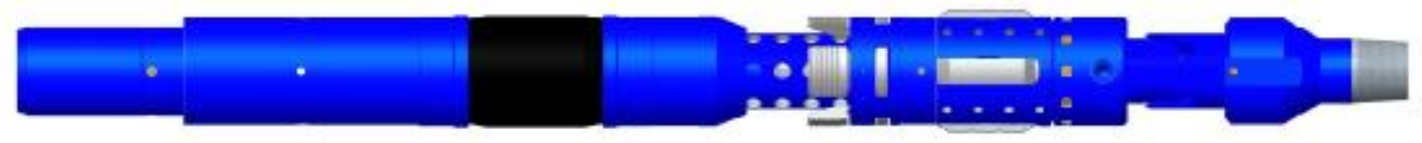

Fig. 1 The structure diagram of drag type of bottom sealed packer

Sealed parts move in under the action of external force and seal ring gap in the end to prevent the passing of fluid. The domestic and foreign existing rubber tube of packer is mostly one-piece. Although it can meet certain requirements, but cannot make up for the shortcomings of its own. After 
in-depth research and analysis, the modular plastic tube is put forward, which take advantage of each other and is a perfect combination.

The role of anchoring section is supporting the packer on the casing wall to prevent from affecting the sealing's performance due to the movement of the longitudinal. The slip we adopted has automatic recovery function, which means that remove the anchor in the process of lifting and recover slip automatically and the cone pushes away slip in the process of put down to achieve seal function.

The function of balancing device is used to balance oil casing annulus pressure after finishing the work so that the packer unlock smoothly.

The main role of the sand control mechanism is to prevent sand card so that make the fracturing sand near rubber tube flow smoothly through sand control channels to the bottom to avoid sand card.

\section{Structure Design and Performance Features}

Whole Structure. Whole structure includes four parts: sealing parts, anchor, balance device and sand control device.

Sealing section is composed of rubber sleeve, top ring, bottom ring and seal center tube. It is the core part of the packer and plays a role of packing annulus.

Anchor is composed of Slip, box of Slip and cone. The box of slip connect to the wiper block carrier, slip and slip spring load on the box of slip and the cone connected with bottom ring of sealing mechanism. The cone take away the slip when to put down, with the effect of packer supporting rubber sleeve when to seal.

Balancing device is composed of valve plate, balancing spring, ball, and internal central tube. Valve plate is sticking spring and ball in internal central tube. The ball closely contact with internal center tube and ball play the role in sealing in the process of work. Remove the pressure of center pipe and ball compress spring under the action of annulus pressure so that create channels between inside and outside to play a role of balance.

Sand control device has functions of sand control through the special design to make the sand can smoothly through the center pipe and the surrounding to avoid sand sticking.

Technical Parameters. Technical parameters of drag type of bottom sealed packer are shown in table 1.

Table 1 The main technical parameters

\begin{tabular}{|c|c|c|c|}
\hline Name & Parameter & Name & Parameter \\
\hline Overall length & $1414[\mathrm{~mm}]$ & $\begin{array}{l}\text { Maximum working } \\
\text { temperature }\end{array}$ & $120\left[{ }^{\circ} \mathrm{C}\right]$ \\
\hline Max outside diameter & $\Phi 116[\mathrm{~mm}]$ & $\begin{array}{l}\text { Maximum operating } \\
\text { pressure differential }\end{array}$ & $70[\mathrm{MPa}]$ \\
\hline Track journey & $235[\mathrm{~mm}]$ & The number of seal & 24 [times] \\
\hline $\begin{array}{l}\text { Outside diameter of } \\
\text { rubber sleeve }\end{array}$ & $\Phi 115[\mathrm{~mm}]$ & Seal diameter & $\begin{array}{c}\Phi 124.3[\mathrm{~mm}] / / 121.4 \\
{[\mathrm{~mm}]}\end{array}$ \\
\hline Thrust & $20-35[\mathrm{kN}]$ & Threaded of both ends & $27 / 8 "$ UP TBG \\
\hline
\end{tabular}

Performance Feature. Sealing structure is simple, rubber sleeve is short, performance of seal is reliable, teeth of slip has high hardness and toughness is relatively good, anchor is firmly and it is suitable for all kinds of grade of steel casing.

It has the seal, support, centralizer and circulation and is compact.

Sealing and unsealing can be easily realize through lift and down string and it is convenient operation simple.

Design sand control device specially to avoid possible sand plug as far as possible in operation. 


\section{Indoor Experiment and Field Test}

Indoor Experiment. In the inner diameter of $124.3 \mathrm{~mm}$ casing, on condition that temperature is 120 ${ }^{\circ} \mathrm{C}$, pressure is $70 \mathrm{MPa}$ and load of sealing and unsealing is $20-35 \mathrm{kN}$, the times of repetitive sealing and unsealing of packer is more than 24 .

In the inner diameter of $121.4 \mathrm{~mm}$ casing, on condition that temperature is $120^{\circ} \mathrm{C}$, pressure is 70 $\mathrm{MPa}$ and load of sealing and unsealing is $20-35 \mathrm{kN}$, the times of repetitive sealing and unsealing of packer is more than 32 .

In the process of the whole experiment, from the many test results of drag type of bottom sealed packer, it's performance of sealing is stable, sealing and unsealing is flexible and anchor is firm. Packer's overall performance is far more than domestic existing level and has reached the foreign advanced level, so it can meet the needs of the field.

Field Test. Select a well for conducting a test of drag type of bottom sealed packer. That well adopts hydraulic sand blasting fracturing technology, annulus sand carrying and fluid infusion in pipeline injection mode. The design of fracturing is 8 segments and construction completion period is 8 segments.

String structure is shown in figure 2. The well adopts hydraulic jet piecewise fracturing string structure (from top to bottom) : guide shoe, drag type of bottom sealed packer, ejector, thick chamfering pipeline, hydraulic safety joint, horizontal chamfering pipeline and thick pipeline into the mud stream.

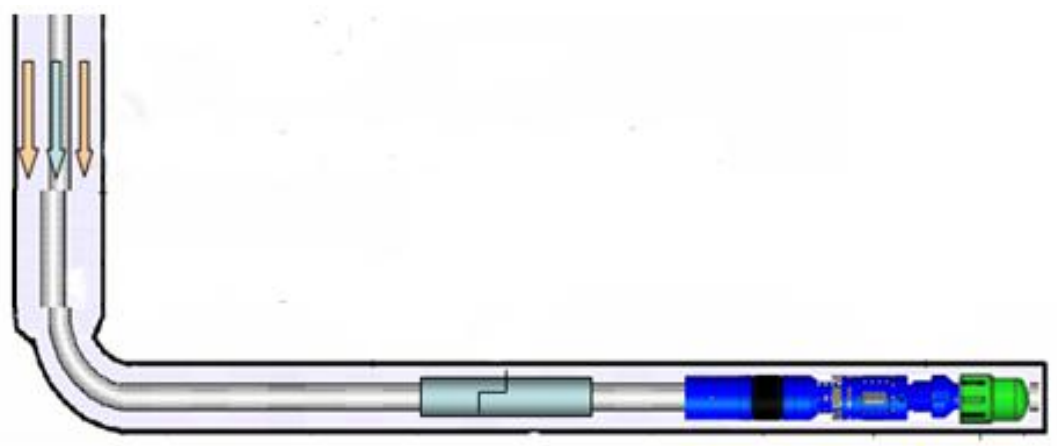

Fig. 2 The continuous layered fracturing string

Use self-developed drag type of bottom sealed packer to complete 8 period of construction. By each fracturing curve is known, working pressure is $40-50 \mathrm{MPa}$ and bursting pressure is $29-50 \mathrm{MPa}$. This means that the performance of the packer is reliable, performance of tool is stability, during the process of fracturing sealing and unsealing is smooth and no sand sticking phenomenon.

The situation of the packer is shown in figure 3 .

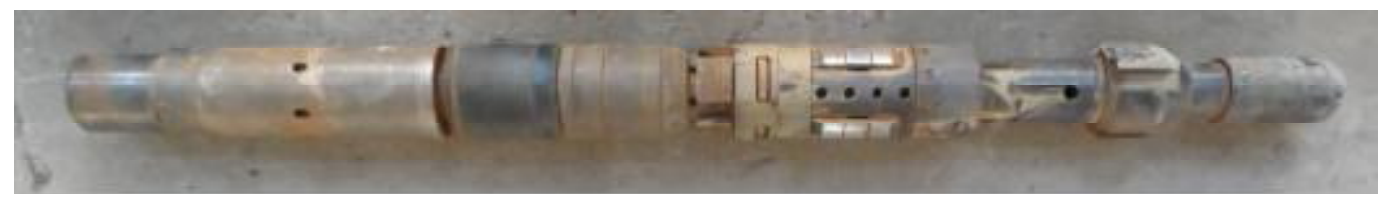

Fig. 3 The overall picture of packer after work has completed

After pulling out, the overall structure is in good condition, there is no obvious deformation after test and the action of every part is flexible.

The inner rubber sleeve is slightly damaged. But it does not affect the sealing performance. After pulling out, the size external rubber sleeve is $\Phi 119 \mathrm{~mm} \times 132 \mathrm{~mm}$, rubber sleeve shortens $16 \mathrm{~mm}$ but increased $4 \mathrm{~mm}$ in diameter direction and the ends of rubber sleeve are slightly damaged but it does not affect the sealing performance. 


\section{Conclusions}

The overall structure includes four parts: sealed portion, supporting anchoring portion, sand control installation and balancing device.

In the inner diameter of $124.3 \mathrm{~mm}$ casing, on condition that temperature is $120{ }^{\circ} \mathrm{C}$, pressure is $70 \mathrm{MPa}$ and load of sealing and unsealing is $20-35 \mathrm{kN}$, the times of repetitive sealing and unsealing of packer is more than 24; In the inner diameter of $121.4 \mathrm{~mm}$ casing, on condition that temperature is $120{ }^{\circ} \mathrm{C}$, pressure is $70 \mathrm{MPa}$ and load of sealing and unsealing is $20-35 \mathrm{kN}$, the times of repetitive sealing and unsealing of packer is more than 32; In the process of the whole experiment, from the many test results of drag type of bottom sealed packer, it's performance of sealing is stable, sealing and unsealing is flexible and anchor is firm.

Use self-developed drag type of bottom sealed packer to complete 8 period of construction. By each fracturing curve is known, working pressure is $40-50 \mathrm{MPa}$ and bursting pressure is $29-50 \mathrm{MPa}$. This means that the performance of the packer is reliable, performance of tool is stability, during the process of fracturing sealing and unsealing is smooth and no sand sticking phenomenon. Through the indoor experiment and field test show that the packer meets the requirements of the site construction, solves the packer's difficulties such as it is unable to bear high temperature and high pressure and the anchor proportion clamp difficultly and stick sand easily and achieve the goal of fracturing more paragraphs by one string. It's overall performance is far more than domestic existing level and has reached the foreign advanced level, so it can meet the needs of the field.

\section{Acknowledgements}

This work and results reported herein are part of Major Scientific and Technological Achievements Transformation and Cultivation Project Z151100002815024 supported by Beijing Municipal Science and Technology Commission, and Project 2014D-5006-0215 supported by PetroChina Innovation Foundation.

\section{References}

[1] Xianhui Zhu, Chunjian Feng: The Development and Application of New Type of Packer in Offshore Jacket Platform, volume 11 of Petroleum Planning \& Engineering, chapter, 6 (2000), p. 32-33.

[2] Lintao Xin, Xinning Sun and Haitao Liu: Development and Application of New Y445 Pressure Difference Release Packer, volume 28 of Oil Drilling \& Production Technology, chapter, 6 (2006), p. 6, 78-80.

[3] Guanglu Chou, Dangsheng Zheng and Hui Zhang: Hydraulic jet pump and it's application advantages and effects, volume 6 of Petroleum Geology and Recovery Efficiency, chapter, 4 (1999), p. 67-71. 